\title{
ONLINE ADGAMES: A NEW TOOL FOR MARKETING COMMUNICATION
}

\author{
Celina Steffen, University of Siegen, Germany \\ Hanna Schramm-Klein, University of Siegen, Germany \\ Sascha Steinmann, University of Siegen, Germany \\ Gunnar Mau, University of Siegen, Germany
}

\begin{abstract}
As a specific form of below the line communication, online adgames have emerged as one recent method of branded entertainment. In contrast to in-game advertising, adgames are developed or adapted by the company itself and further serve as a means to publish the advertising message. The potential of advertising with computer games becomes apparent from the growth rates of this industry. Furthermore, there is an increasing number of companies that are using games to support their brands, e.g. by placing adgames on their homepage or by providing adgames for mobile web applications.

The aim of our study is to investigate how playing an adgame is able to influence consumers' evaluations and attitudes towards a brand, brand loyalty, and buying behavior, especially, the seldom-researched topic of flow within adgames, which refers to a state in which the player is completely absorbed by the adgame, as well as its influence on the outcome of adgames are investigated by this study. Flow is defined as an intrinsic motivation or enjoyment in an activity. It is specifically computer games that are regarded as means with a high propensity to evoke a status of flow. Based on both the ELM and excitation transfer theory we assume that flow experiences positively influence both the evaluation of the adgame as well as the evaluation of the advertised brand. Previous studies have shown that brands placed within a game are perceived more positively than brands which are not included in the game. Based on the dual mediation hypothesis we therefore assume that there is a positive influence of the evaluation of the adgame on brand evaluation. Beyond positive evaluations of the adgame, classical conditioning mechanisms trigger positive brand attitudes by the game player. Furthermore, findings of previous studies have shown a positive influence of brand evaluation on brand attitude. Positive attitudes influence loyalty and also indirectly - have a positive impact on buying behavior. Beyond that, there is a direct impact of attitude on buying behavior.
\end{abstract}

Flow experience was conceptualized as a two-dimensional construct. We chose a reflective measurement approach for both dimensions of intrinsic enjoyment and escapism. We conceptualized brand attitude and loyalty as reflective constructs based on previous studies, as the use of established scales is advisable. Since the evaluation of game and brand reflect a composite of particular indicators across different, unique attributes, it is expedient to operationalise them effectively in a formative rather than reflective way. To test our model, an online game placed on the homepage of a large European brewery during the Christmas season was used as object for our research. Using a standardized questionnaire, we conducted an online survey among consumers who played this game. A total of 5,522 usable questionnaires remained for the investigation. To test our hypotheses, we conducted PLS regression. The results show that flow has a significant and high positive impact on the evaluation of the adgame and a significant but lower effect on the evaluation of the brand. Our results show a significant and high positive effect of evaluation of the adgame on brand evaluation, but only a small positive effect of evaluation of the adgame on brand attitude. The positive influence of evaluation of the brand on attitude toward the brand is confirmed based on the empirical analysis. Thus, brand attitude is indirectly affected by the evaluation of the adgame through the evaluation of the brand. The effect of game evaluation on brand evaluation is relatively strong, which has a high impact on the attitude toward the brand in return. Furthermore, our results show a significant and high positive effect of brand attitude on loyalty. Moreover, the influence of both loyalty and brand attitude on buying behaviour is highly significant.

Our study points to high relevance of online adgames as an instrument for an effective advertising strategy by showing that playing an adgame has a positive impact on brand attitude, loyalty, and buying behaviour. The relatively low effect of game evaluation on brand attitude might be explained by the high profile of the brand by the participants. We were able to show that enjoyment and interactivity are important attributes of an adgame because this results in a positive evaluation of the game. Flow experience increases players' enjoyment of the adgame which causes in an enhanced processing of the peripheral advertising message. The experience of flow that the player is experiencing when playing has the effect that the game player's awareness of the commercial character of the adgame is fading into the background. Therefore, we assume that in contrast to classical advertising, adgames are able to convey the advertising message subconsciously which increase the effect of them. These findings imply consequences for managerial practice as well as for future research.

References available upon request 